\title{
Effect of the Biocontrol Yeast Rhodotorula glutinis Strain LS11 on Patulin Accumulation in Stored Apples
}

\author{
Raffaello Castoria, Valeria Morena, Leonardo Caputo, Gianfranco Panfili, \\ Filippo De Curtis, and Vincenzo De Cicco
}

First, second, fifth, and sixth authors: Dipartimento di Scienze Animali, Vegetali e dell'Ambiente, Università del Molise, Via F. De Sanctis, 86100, Campobasso, Italy; third author: Istituto di Scienze delle Produzioni Alimentari, C.N.R. Via G. Amendola 122/O, 70126 Bari, Italy; and fourth author: Dipartimento di Scienze e Tecnologie Agro-Alimentari, Ambientali e Microbiologiche, Università del Molise, Via F. De Sanctis, 86100, Campobasso, Italy. Accepted for publication 27 June 2005.

\begin{abstract}
Castoria, R., Morena, V., Caputo, L., Panfili, G., De Curtis, F., and De Cicco, V. 2005. Effect of the biocontrol yeast Rhodotorula glutinis strain LS11 on patulin accumulation in stored apples. Phytopathology 95:1271-1278.

Contamination of apples (Malus domestica) and derived juices with fungicide residues and patulin produced by Penicillium expansum are major issues of food safety. Biocontrol agents represent an alternative or supplement to chemicals for disease control. Our data show that these microbes could also contribute to actively decreasing patulin accumulation in apples. Three biocontrol agents, Rhodotorula glutinis LS11, Cryptococcus laurentii LS28, and Aureobasidium pullulans LS30, were examined for their in vitro growth in the presence of patulin and for their capability to

decrease mycotoxin recovery from the medium. Strain LS11 yielded the highest growth rates and the greatest decrease of toxin recoveries. Further, it caused the appearance of two major spots on thin-layer chromatography (TLC) plates, suggesting possible metabolization of the mycotoxin. In vivo, i.e., in the low percentage of LS11-pretreated apples infected by $P$. expansum, patulin accumulation was significantly lower than in nontreated infected fruits. Yeast cells survived and increased in infected apples and, in a model system emulating decaying apple, resulted in accelerated breakdown of patulin and the production of the same TLC spots as those detected in vitro. These data suggest that biocontrol yeast cells surviving in decaying apples could metabolize patulin and/or negatively affect its accumulation or synthesis. To our knowledge, this is the first report describing the effect of a biocontrol agent on patulin accumulation in vivo.
\end{abstract}

Patulin is a secondary metabolite synthesized by a number of anamorphic fungal genera. It is a polyketide originally considered an antibiotic (25), but now recognized as a mycotoxin displaying diverse toxic effects: immunosuppression, embryo and maternal toxicity in mice, and genotoxicity $(2,15,22)$. A major producer of patulin is the fungus Penicillium expansum Link., an important postharvest pathogen of pome fruits, which causes accumulation of the toxin in infected apples and pears. As a consequence, patulin contaminates derived juices, very popular beverages for children, and pome fruit-based baby foods $(1,29)$. Patulin has also been detected in unfermented cherry and blackcurrant juices (18). Therefore, it represents a serious health hazard and a major issue for food safety (8). The maximum tolerable levels of this mycotoxin have been established for fruit-derived products in many countries including the United States (10) and, recently, the European Union (9). However, pre- and postharvest fungicide treatments cannot completely prevent infection by $P$. expansum, and the difficulty of selecting healthy fruits on an industrial scale does not ensure the absence of patulin in the final product (11).

In the last few years, public concern regarding fungicide residues in food has steadily increased. Further, fungicides have become increasingly ineffective because of the development of resistant strains in pathogen populations (31), while restrictions are currently being established in many countries. Biocontrol agents (BCAs) have been successfully applied as an alternative or supplement to fungicides to prevent postharvest diseases of different

Corresponding author: R. Castoria; E-mail address: castoria@ unimol.it

DOI: 10.1094/PHYTO-95-1271

(c) 2005 The American Phytopathological Society fruits, and some postharvest BCAs have been commercialized $(17,34)$. Many postharvest BCAs are yeasts. Studies are being carried out on the mechanisms of action of biocontrol yeasts to enhance their efficacy, and it has been proposed that they be used for this purpose even before harvest $(3-5,7,12,16,17,36)$. Fermentative yeasts reduce patulin contamination during production of cider from apple juice (14). Moss and Long showed that Saccharomyces cerevisiae metabolizes patulin to the less toxic Eascladiol $(26,32)$, whereas no reports exist on the effect of biocontrol yeasts on patulin accumulation in stored pome fruits.

The aim of our study was to assess the influence of a BCA on patulin accumulation in apples in which mycotoxin synthesis by $P$. expansum occurs. For this purpose, we examined three BCAs, previously shown to be effective against the major postharvest pathogens on stored apples and other commodities $(4,20,21)$, for their capability of growing in the presence of patulin and to decrease mycotoxin concentration in vitro. These experiments allowed us to select Rhodotorula glutinis strain LS11 as the BCA showing the greatest growth and the greatest decrease of toxin concentration. Therefore, we examined this biocontrol yeast for its effects on the accumulation of patulin in P. expansum-infected apples, and studied the possible mechanism(s) causing these effects. To our knowledge, this is the first report describing the influence of a BCA on mycotoxin accumulation in situ, i.e., where fungal growth and mycotoxin synthesis occur. Implications on the prevention and/or possible detoxification of patulin contamination in apple-based juices are also discussed.

\section{MATERIALS AND METHODS}

All solvents used were high-performance liquid chromatography (HPLC) grade from Merck AG (Darmstadt, Germany). The 
patulin reference standard was purchased from Sigma (SigmaAldrich Co., St. Louis).

Apples. Apples (cv. Annurca) harvested from the same orchard and kept at $5^{\circ} \mathrm{C}$ for 3 to 6 months after harvest were used in all experiments. Prior to the experiments, apples were kept at room temperature for $24 \mathrm{~h}$, their surfaces were disinfested with $1 \%$ commercial sodium hypochlorite for $2 \mathrm{~min}$ and then rinsed with sterile distilled water.

BCAs and fungal pathogen. All microbial strains used in this study were obtained from the culture collection of the Dipartimento di S.A.V.A., Università del Molise. The BCAs were the yeasts $R$. glutinis strain LS11 and Cryptococcus laurentii strain LS28, and the yeastlike fungus Aureobasidium pullulans strain LS30, which were originally isolated from olives (LS11) and apples (LS28 and LS30) and selected for their protective activity against different postharvest pathogens on different crops (3-5, 20,21). The apple fungal pathogen was $P$. expansum FS-7, a highly virulent isolate from the same culture collection.

In vitro incubation of BCAs with patulin and analyses of mycotoxin persistence. The BCAs LS11, LS28 and LS30 were grown in $50 \mathrm{ml}$ of Lilly-Barnett (LB) medium (19) in shake cultures at $23^{\circ} \mathrm{C}$ for 24 to $36 \mathrm{~h}$. Cultures were centrifuged for $20 \mathrm{~min}$ at 4,000 to $8,000 \mathrm{rpm}$ (depending on the BCA), the cells were resuspended in $\mathrm{LB}$, and their concentrations were adjusted to $1.0 \times 10^{5} \mathrm{CFU} / \mathrm{ml}$, corresponding to values of 0.01 optical density (OD) at $595 \mathrm{~nm}$. Two hundred microliters of these suspensions was incubated for 10 days at $23^{\circ} \mathrm{C}$ in sterile 96-well microtiter plates in the presence of 100,250 , or $500 \mu \mathrm{g}$ of patulin per $\mathrm{ml}$. Controls were the same BCAs grown in the absence of patulin or with hygromycin B at $100 \mu \mathrm{g} / \mathrm{ml}$; the latter antibiotic was used to test the suitability of experimental conditions for assessing toxicity to the biocontrol strains (positive control). Growth was monitored on a daily basis by reading OD at $595 \mathrm{~nm}$ in a microplate Reader (Bio-Rad Laboratories, Hercules, CA) (23). OD values were converted to CFU per milliliter by comparing OD values of each BCA with previously plotted standard curves. In these experiments, 12 replicates (i.e., 12 wells) were prepared for each BCA at each patulin concentration, and the mean growth and standard deviation were calculated for each treatment by sampling 6 of the 12 wells.

For assessing patulin persistence in the medium after incubation, contents of the same six wells used for growth determination were pooled in a pair-wise fashion and centrifuged at 4,000 to $8,000 \mathrm{rpm}$. Patulin was extracted as described by MacDonald et al. (24) with slight modifications. Equal volumes of ethyl acetate were added three times to the supernatants. Solvent fractions were pooled, cleaned up with $200 \mu \mathrm{l}$ of $1.5 \%$ (wt/vol) sodium carbonate solution, and dehydrated by adding $0.2 \mathrm{~g}$ of anhydrous sodium sulfate. Samples in organic solvent were transferred to new vials and ethyl acetate was removed under an $\mathrm{N}_{2}$ stream. Dried samples were finally redissolved in water acidified with acetic acid $(\mathrm{pH}=4)$ before HPLC analyses. Patulin persistence in LB was expressed as mean percentage of recovery compared with samples of the medium, without BCAs, to which the toxin was added at different concentrations and extracted immediately after addition. Also, cell pellets collected by the above-mentioned centrifugation were extracted with ethyl acetate in order to assess the adsorption of the toxin to cell walls of BCAs or its presence within the cells (data not shown).

For qualitative analyses, the incubation of BCAs in the six remaining wells was stopped at days 5 and 10 (three wells per day). Unextracted 20- $\mu$ l aliquots of the cell-free supernatant from single wells were loaded on thin-layer chromatography (TLC) plates that were developed as described below. Data reported in this study involved the incubation of BCAs with patulin at a concentration of $250 \mu \mathrm{g} / \mathrm{ml}$. Controls were unextracted aliquots of the cell-free medium of BCAs incubated without patulin, of toxin-amended uninoculated medium and of uninoculated LB without toxin. All experiments were performed three times.
Antagonist activity assay of strain LS11. The determination of antagonist activity was performed as previously described (3$5,20)$. The BCA LS11 was grown in $50 \mathrm{ml}$ of LB medium as described previously. Cells were collected by centrifugation, washed twice with sterile distilled water, and suspended in the same solvent at a concentration of $1 \times 10^{6} \mathrm{CFU} / \mathrm{ml}$. Two wounds ( $3 \mathrm{~mm}$ wide $\times 3 \mathrm{~mm}$ deep) per apple were made with a sterilized cork borer at the equator. Thirty microliters of the yeast cell suspension was added to each wound immediately after wounding. After 1 to $1.5 \mathrm{~h}$, wounds were inoculated with $15 \mu \mathrm{l}$ of a freshly prepared spore suspension of $P$. expansum isolate FS-7 in sterile distilled water $\left(1 \times 10^{4}\right.$ conidia per $\left.\mathrm{ml}\right)$. Apple wounds pretreated with $30 \mu \mathrm{l}$ of sterile distilled water prior to inoculation with $P$. expansum were the control. Each treatment consisted of three replicates with 40 apples per replicate. Apples were kept at $23^{\circ} \mathrm{C}$ in the dark at $90 \%$ relative humidity $(\mathrm{RH})$ up to 6 days. The number of infected wounds and mean lesion diameters were recorded from the fourth to the sixth day, when all the wounds were infected by the pathogen in control treatments, and disease incidence in LS11-treated and nontreated apples was expressed as percentage of infected wounds (data not shown). Disease severity was expressed as mean lesion diameters in LS11-treated and untreated apples. Experiments were performed three times.

Patulin accumulation in infected apples. Patulin accumulation was sampled in the same apples as those used in the assays of antagonist activity, pretreated and not pretreated with the BCA LS11 prior to pathogen inoculation. At 4 and 6 days after the beginning of the experiments, decaying tissue plus $1 \mathrm{~cm}$ of surrounding healthy tissue were withdrawn from apple wounds in which infection by $P$. expansum was evident. Thirty decayed wounds (10 from five apples in each replicate, described previously) were taken from each treatment at each time interval, pooled, ground in an ice-cooled Waring blender, and divided in three 10-g subsamples. Patulin was extracted as described by MacDonald et al. (24). Briefly, each subsample was treated with pectinase in the presence of $10 \mathrm{ml}$ of distilled water. After centrifugation, all the subsequent steps were performed as in previously described in vitro experiments, by using proportional amounts of the same reagents and by pouring samples through anhydrous sodium sulfate. Finally, dried samples were dissolved in acidified water $(\mathrm{pH}=4)$ before HPLC analyses. Patulin accumulation was expressed as micrograms per gram of decaying tissue. Experiments were performed three times.

Incubation of strain LS11 with patulin in pathogen-free macerated and browning apple tissue. A pathogen-free model system was developed in order to assess the capability of the BCA LS11 to decrease patulin contamination and to produce putative toxin metabolite(s) in apple tissue having characteristicsmaceration, browning due to phenol oxidation, etc.- similar to decaying apple infected by $P$. expansum. Unpeeled apple fruits were homogenized in a Waring blender with sterile distilled water at a ratio of $1 \mathrm{ml} / \mathrm{g}$ of apple and left overnight at $4^{\circ} \mathrm{C}$ to allow browning to occur. After $2 \mathrm{~h}$ at room temperature $\left(23^{\circ} \mathrm{C}\right), 4.5 \mathrm{ml}$ of homogenized apple tissue was amended with patulin (final concentration $250 \mu \mathrm{g} / \mathrm{ml}$ ) and inoculated with LS11 (final concentration $1 \times 10^{7}$ cells per $\mathrm{ml}$ ) in $60-\mathrm{ml}$ sterile polypropylene tubes. Controls consisted of uninoculated homogenized browning apple tissue with and without patulin and LS11-inoculated homogenized browning apple tissue without patulin. The tubes were prepared in triplicate and kept at $23^{\circ} \mathrm{C}$ up to $144 \mathrm{~h}$. Patulin was extracted after $24,48,72$, and $144 \mathrm{~h}$ and samples were analyzed quantitatively by HPLC. The entire content of tubes of each replicate at each time interval was used for patulin determinations and for assessment of population dynamics of strain LS11 (described below). Patulin was expressed as a mean percentage of recovery compared with the amount of toxin added to uninoculated homogenized browning apple tissue and extracted immediately after addition. For qualitative analyses, unextracted sample aliquots 
were withdrawn at 2 and 6 days and examined by TLC as described below. Experiments were performed three times.

Population dynamics of strain LS11. Colony-forming units of the BCA LS11 were determined in P. expansum-infected wounds and in pathogen-free macerated and browning apple tissue at the same time intervals at which quantifications of patulin were carried out. For determination in $P$. expansum-infected apples, decayed tissue was withdrawn from single wounds from three different apples and samples were transferred to flasks containing $50 \mathrm{ml}$ of sterile $\mathrm{H}_{2} \mathrm{O}$. After agitation at $200 \mathrm{rpm}$ and $23^{\circ} \mathrm{C}$ for $20 \mathrm{~min}$, appropriate dilutions were plated in triplicate on Basal yeast agar (BYA) amended or not with sulfate salts of ampicillin and streptomycin. For determination in pathogen-free macerated and browning apple tissue, $0.5 \mathrm{ml}$ of tissue was added to $4.5 \mathrm{ml}$ of sterile $\mathrm{H}_{2} \mathrm{O}$ and the following steps were as described above (data not shown). Pink cells of the BCA LS11 were identified by colony color and morphology. Data are presented as mean $10^{7} \mathrm{CFU}$ per infected wound \pm standard deviation. Experiments were performed three times. The identity of randomly collected pink colonies was confirmed by amplified fragment length polymorphism (AFLP) analysis of extracted DNA (data not shown), as previously described (20).
TLC and HPLC analyses. TLC qualitative analyses were performed as previously described (6). Samples were loaded on aluminum-backed silica gel $60 \mathrm{~F}_{254}$ plates, and chromatography was performed at room temperature in glass tanks by using toluene/ethyl acetate/formic acid 5:4:1 ( $\mathrm{vol} / \mathrm{vol} / \mathrm{vol})$ as the solvent system. Plates were then sprayed with a $0.5 \%$ solution of 3-methyl-2-benzothiazolinone hydrazone (MBTH) (wt/vol) and heated at $120^{\circ} \mathrm{C}$ for $15 \mathrm{~min}$.

Patulin analysis was done by HPLC as described by MacDonald et al. (24) with slight modifications by using a Kontron HPLC analytical system (Kontron, Milan, Italy) (325 apparatus), equipped with a 20- $\mu$ l loop, autosampler (HPLC 360). The UV detector (HPLC 335) set at $276 \mathrm{~nm}$ was connected to a data integration system and a $250-\times 4.6-\mathrm{mm}$ internal diameter, $5 \mu \mathrm{m}$ Supelco LC18 column. The mobile phase was acidified water/ acetonitrile 9:1 ( $\mathrm{vol} / \mathrm{vol})$ with a flow rate of $1 \mathrm{ml} / \mathrm{min}$ and a total run of $15 \mathrm{~min}$. Standard serial solutions of patulin in acidified water were injected and peak areas were determined to generate standard curve data for quantitative analyses.

Statistical analysis. Data obtained in the three repetitions of all experiments were similar so they were pooled and analyzed with the SPSS program (SPSS Inc., Chicago, IL, release 8.0.0 for
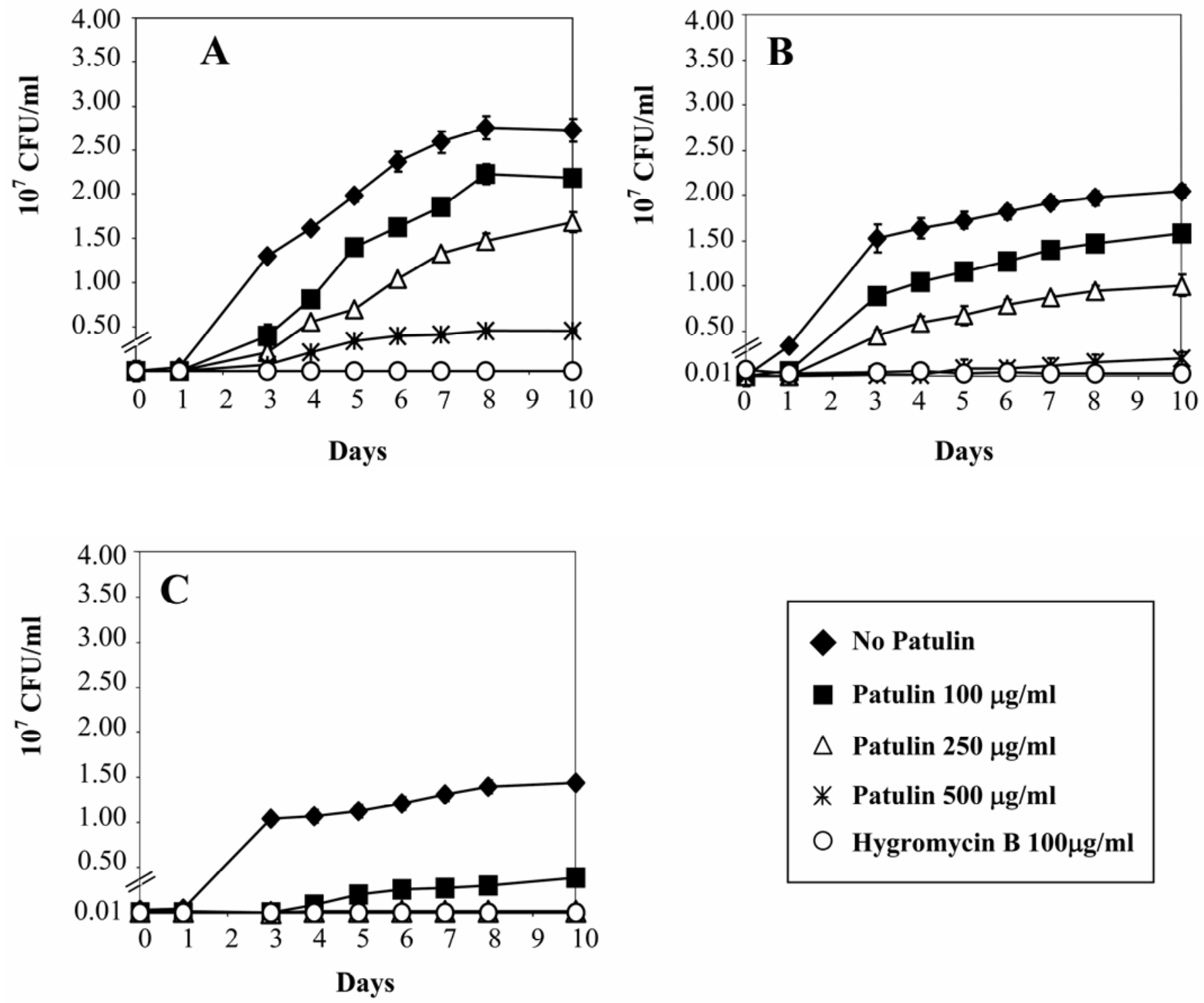

Fig. 1. In vitro growth $\left(10^{7} \mathrm{CFU} / \mathrm{ml}\right)$ of the biocontrol agents A, Rhodotorula glutinis LS11, B, Cryptococcus laurentii LS28, and C, Aureobasidium pullulans LS30 in Lilly-Barnett medium in the absence and in the presence of 100, 250, and $500 \mu \mathrm{g}$ of patulin per ml and of $100 \mu \mathrm{g}$ of hygromycin B per ml. Data from three different experiments were pooled. Values are the means \pm standard deviation of the mean $(n=18)$. 
Windows). All percentages were converted to Bliss angular values (arcsine $\sqrt{\%}$ ) before statistical analyses. In vitro growth of BCAs in the presence of different patulin concentrations and population dynamics of strain LS11 in decaying parts of $P$. expansum-infected apples were calculated, respectively, as mean $10^{7} \mathrm{CFU} / \mathrm{ml} \pm$ standard deviation $(n=18)$ and mean $10^{7} \mathrm{CFU}$ per infected wound \pm standard deviation $(n=9)$. The set of experiments concerning patulin recovery from in vitro cultures of the BCAs and experiments with the pathogen-free model system were each arranged in a full factorial design, and the percentage of mycotoxin recovery was analyzed by using the general linear models procedure. Mean values from these experiments were separated with the least significant difference (LSD) test $(P=$ $0.001)$. In time-course experiments of patulin recovery from the model system, the percent values of patulin recoveries were regressed versus time intervals (hours) of toxin analysis by using the SPSS regression procedure to determine intercepts, slopes, and Pearson R-square coefficients. Mean lesion diameters (disease severity) in LS11-treated and nontreated apples infected by $P$. expansum and mean values of patulin accumulation in LS11-treated and nontreated infected apples were compared at each time interval within each experiment with the Student's $t$ test.

\section{RESULTS}

Identification of the BCA(s) tolerant to patulin. Rhodotorula glutinis strain LS11 was the BCA most tolerant to patulin. LS11 and $C$. laurentii LS28 were able to grow in the presence of patulin in a dose-dependent fashion: respective growth rates were higher at lower mycotoxin concentrations (Fig. 1A and B). The highest growth rates were recorded with biocontrol strain LS11, which grew even in the presence of patulin at a concentration of $500 \mu \mathrm{g} / \mathrm{ml}$. Aureobasidium pullulans strain LS30 displayed delayed and barely detectable growth starting after 3 to 4 days of incubation and only at the lowest mycotoxin concentration (100 $\mu \mathrm{g} / \mathrm{ml})$ (Fig. 1C).

Patulin recovery from growth medium of BCAs. After 10 days of incubation in LB medium amended with varying concentrations of patulin, HPLC analyses showed that recovery of patulin was lowest with $R$. glutinis strain LS11 at all mycotoxin concentrations (Fig. 2). Factorial analysis showed that the effects of different patulin concentrations, BCAs, and their interaction were highly significant $(P<0.001)$ (Table 1$)$. Rodotorula glutinis strain LS11 resulted in 82, 61, and $42 \%$ decreases of patulin recovery at 100,250 , and $500 \mu \mathrm{g} / \mathrm{ml}$, respectively, compared with uninoculated controls. On a percent basis, the higher the initial patulin concentration the greater the recovery of the mycotoxin. An analogous pattern of patulin recoveries was recorded with C. laurentii LS28, which yielded 47, 29, and $16 \%$ decreases at 100,250 , and $500 \mu \mathrm{g} / \mathrm{ml}$, compared with respective uninoculated controls. A. pullulans LS30 caused a $68 \%$ patulin decrease that was more pronounced than LS28, but only at the lowest concentration tested $(100 \mu \mathrm{g} / \mathrm{ml})$, whereas no significant decreases were recorded at higher concentrations.

TABLE 1. Analysis of variance for the influence of three patulin concentrations (dose) and three biocontrol agents (BCAs) or absence of BCAs (treatment) on percentage of patulin recovery

\begin{tabular}{lrrrrc}
\hline $\begin{array}{l}\text { Source } \\
\text { of variability }\end{array}$ & df & \multicolumn{1}{c}{ SS $^{\mathrm{a}}$} & \multicolumn{1}{c}{ MS $^{\mathrm{b}}$} & \multicolumn{1}{c}{$F$} & $P^{\mathrm{c}}$ \\
\hline Treatment (A) & 3 & $52,356.028$ & $17,452.009$ & $1,511.557$ & 0.000 \\
Dose (B) & 2 & $31,621.685$ & $15,810.843$ & $1,369.412$ & 0.000 \\
$\mathrm{~A} \times \mathrm{B}$ & 6 & $14,145.056$ & $2,357.509$ & 204.189 & 0.000 \\
Error & 96 & $1,108.389$ & 11.546 & $\ldots$ & $\ldots$ \\
Total & 107 & $99,231.157$ & $\ldots$ & $\ldots$ & $\ldots$ \\
\hline
\end{tabular}

a Sum of squares.

b Mean of squares.

c Significance at $P=0.001$.

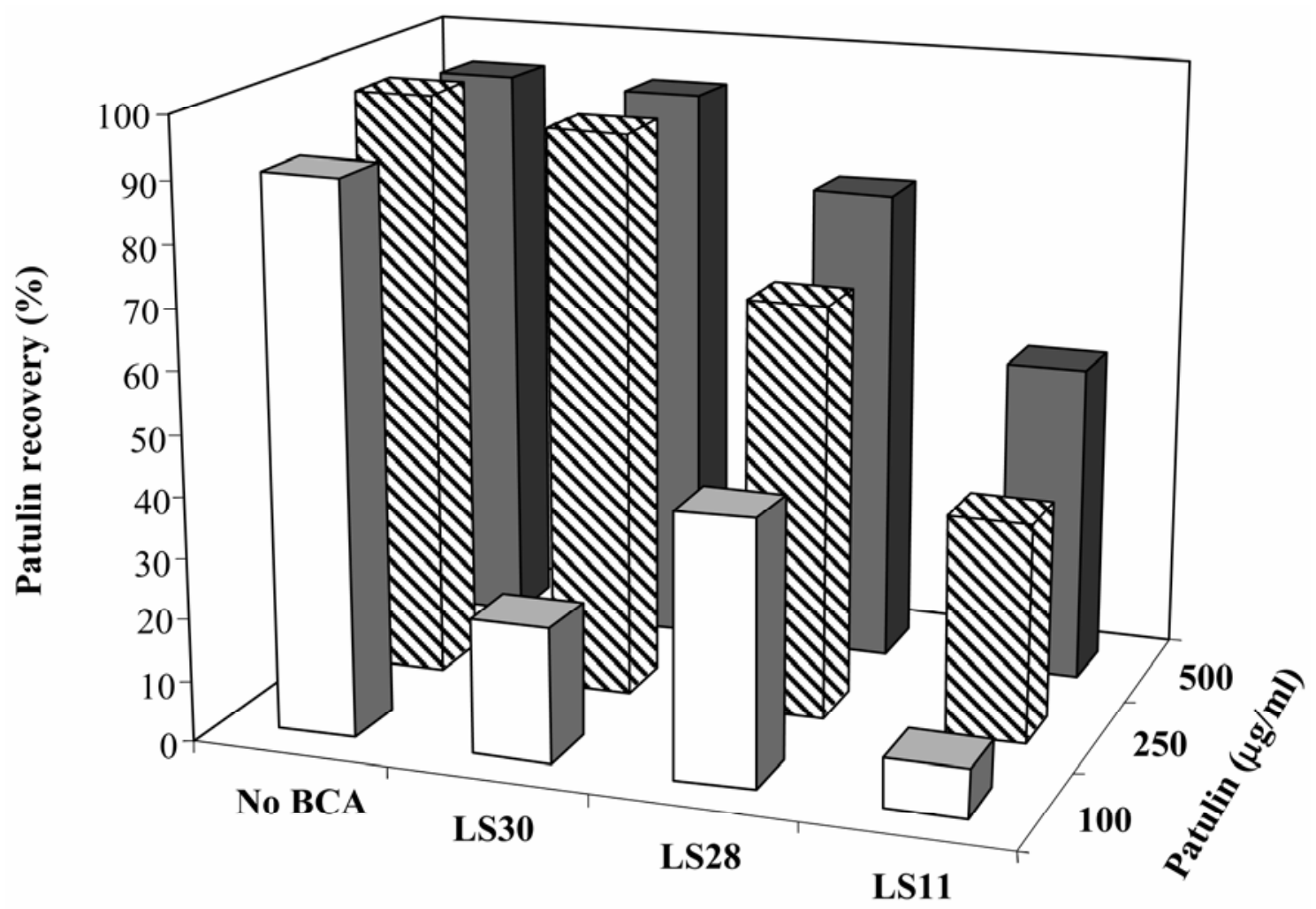

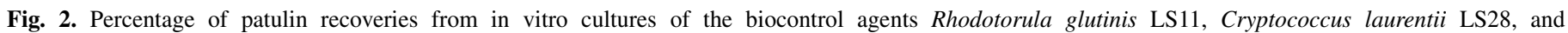

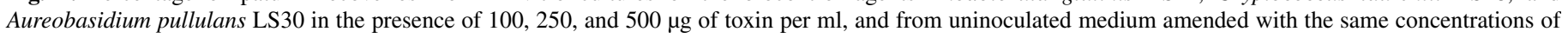
toxin. Data from three different experiments were pooled and means were separated by the least significant difference $(\mathrm{LSD})$ test $(P=0.001)$. LSD $=1.602 \%$. 
Interestingly, TLC analyses showed the appearance of two major spots, with $\mathrm{R} f$ (retention factor) $=0.46$ and $\mathrm{R} f=0.38$, respectively, in the lanes corresponding to LS11 plus patulin at 5 and 10 days incubation, and to LS28 plus patulin at the latest time. The spot with the higher $\mathrm{R} f$ was also evident under UV light before MBTH spraying. As expected, patulin appeared as a yellow spot with $\mathrm{R} f=0.58$. In the LS11 plus patulin lanes, the intensities of the new spots were the highest and increased at 10 days compared to 5 days. In all lanes where these spots appeared, the greater their intensity the lower was that of patulin. No new spots were recorded in all the other lanes, including those with strain LS30, in which the intensity of the patulin spot was comparable to that of the toxin-containing control (data not shown).

Antagonist activity of strain LS11 against $P$. expansum on apples. Under our experimental conditions, biocontrol yeast strain LS11 effectively protected apples from $P$. expansum infections. After 4 days, control apple wounds (not treated with the BCA) were all infected, whereas infection took place in only $16 \%$ of the LS11-treated apple wounds (data not shown). Mean lesion diameters increased throughout the experiment but more slowly in apples treated with the BCA than in respective nontreated controls, reaching, after 4 and 6 days, approximately 12 and $18 \mathrm{~mm}$

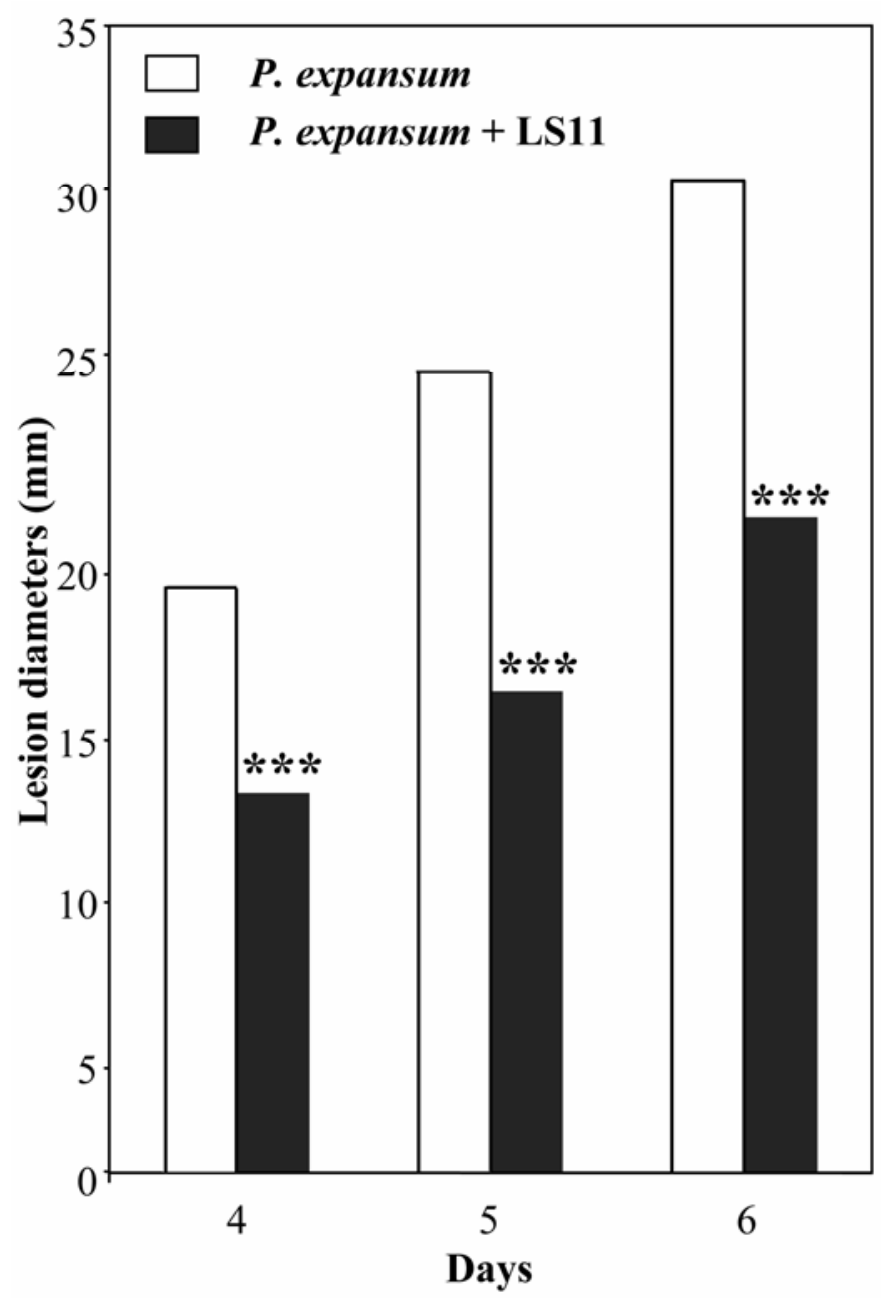

Fig. 3. Disease severity, expressed as mean lesion diameters, in apples artificially inoculated with Penicillium expansum isolate FS-7, pretreated or not with the biocontrol agent Rhodotorula glutinis LS11. Mean lesion diameters were recorded and compared at 4, 5, and 6 days after inoculation. Data from three experiments were pooled. Values marked with symbols (***) indicate very significant differences (at $P=2.0 \times 10^{-5}, P=4.5 \times 10^{-5}$, and $P=4.7 \times$ $10^{-5}$ at 4,5 , and 6 days after inoculations, respectively) according to the Student's $t$ test. and 21 and $31 \mathrm{~mm}$ in LS11-treated and nontreated apples, respectively (Fig. 3).

Determination of patulin in apples infected by $P$. expansum. Patulin contamination of decaying areas of apples artificially inoculated with $P$. expansum, pretreated or not with the BCA LS11, is shown in Figure 4. After 6 days, a slight increase of mycotoxin contamination was recorded both in LS11-treated and nontreated apples compared with mean values observed after 4 days. More importantly, the presence of the BCA significantly lowered mycotoxin levels by $44.9 \%$ at 4 days and $39.3 \%$ at 6 days after the beginning of the experiments compared with control apples not treated with the biocontrol yeast (12.2 versus $22.1 \mu \mathrm{g} / \mathrm{g}$ of decaying apples at 4 days, and 14.8 versus $24.4 \mu \mathrm{g} / \mathrm{g}$ at 6 days).

Persistence and growth of LS11 cells in infected apples. Yeast cells applied in apple wounds at the beginning of the experiments are able to survive and multiply in decaying apple tissue infected with $P$. expansum (Fig. 5), i.e., when LS11 is not able to prevent infection of the wound. The CFU of LS11 increased to $2.2 \times 10^{7}$ per wound 4 days after application, remaining nearly stable after 6 days. In addition to pathogen, we recovered only pink yeast cells from decayed apple wounds both in antibiotic-amended and in antibiotic-free BYA, and AFLP

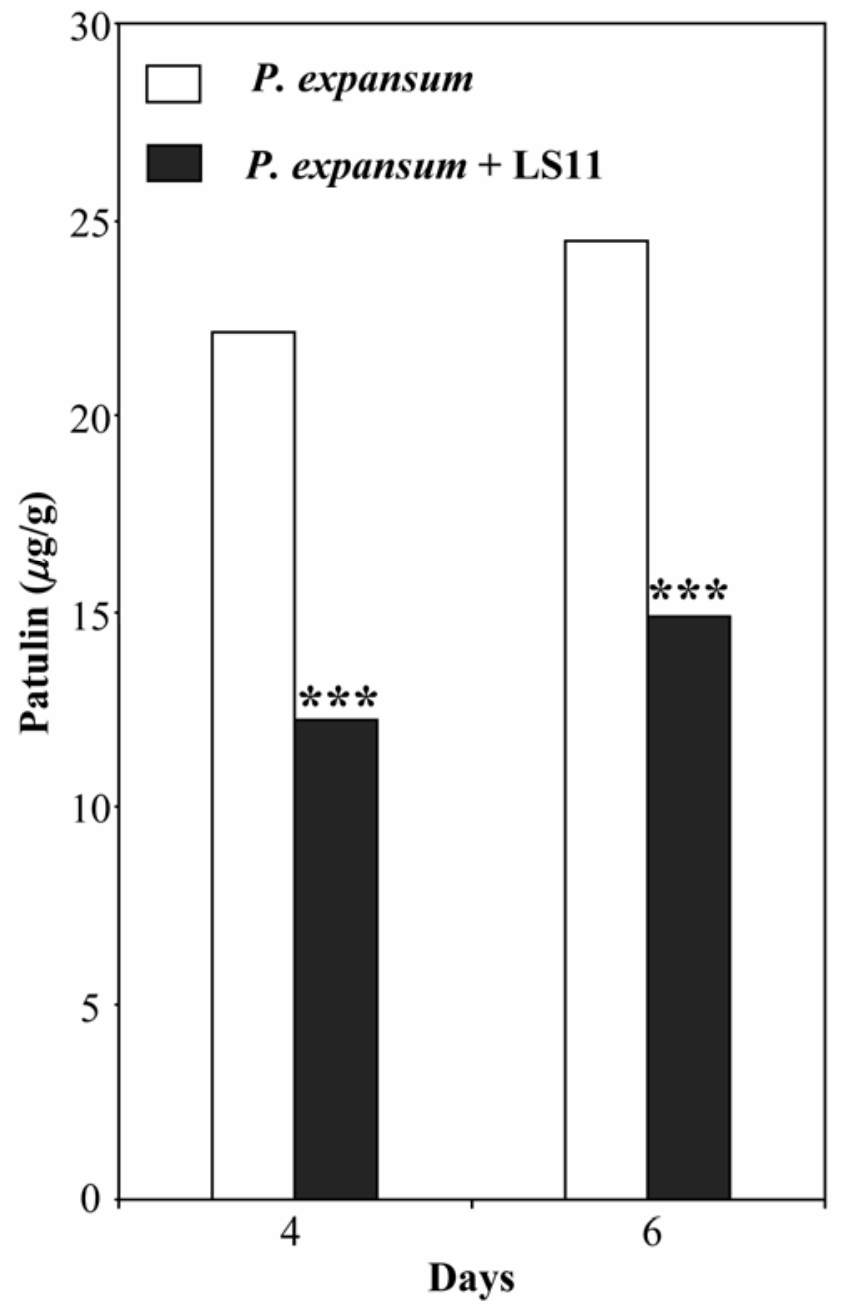

Fig. 4. Patulin accumulation, expressed as micrograms per gram of rotting apple tissue, in apples infected with Penicillium expansum isolate FS-7, pretreated or not with the biocontrol agent Rhodotorula glutinis LS11. Mean patulin contents were measured and compared at 4 and 6 days after artificial inoculation of wounds with fungal conidia. Data from three different experiments were pooled. Values marked with symbols $(* * *)$ indicate very significant differences (at $P=8.7 \times 10^{-5}$ and $P=2.0 \times 10^{-5}$ at 4 and 6 days after inoculations, respectively) according to the Student's $t$ test. 
analyses on randomly collected pink colonies displayed the same electrophoretic pattern as strain LS11 (data not shown).

Recovery of patulin from pathogen-free macerated and browning apple tissue incubated with LS11. The potential metabolization of patulin by LS11 was assessed in pathogen-free macerated and browning apple tissue, used as a model system that emulated decaying of apples following pathogen invasion (Fig. 6). The relationship of patulin recovery versus time was well

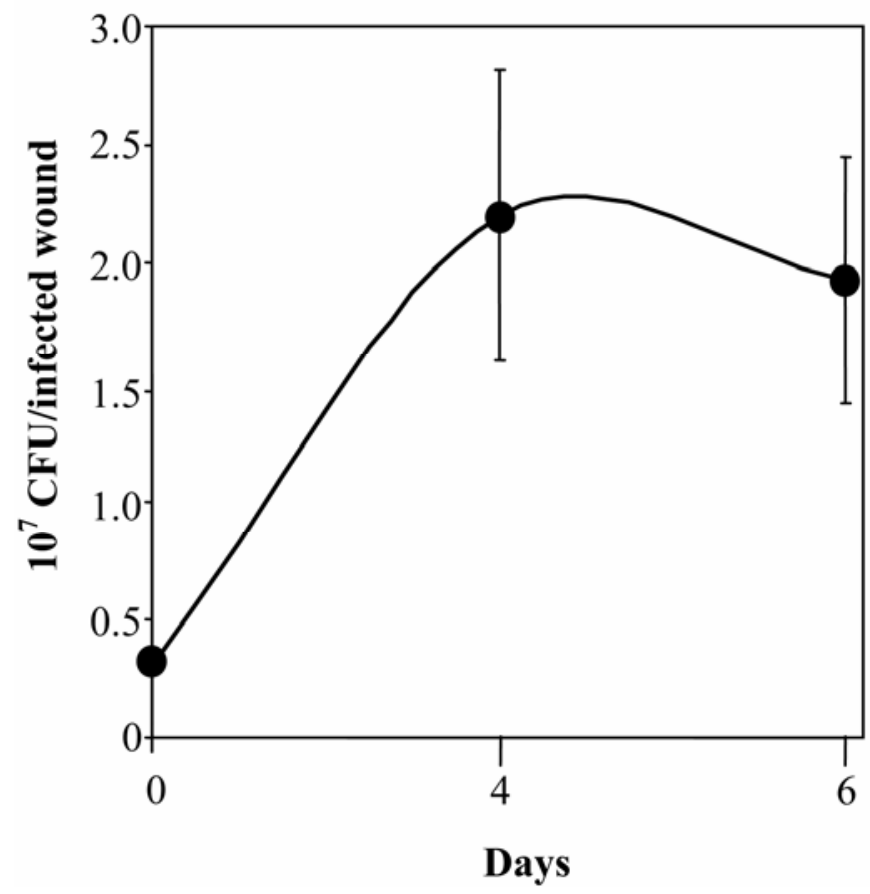

Fig. 5. Population dynamics of Rhodotorula glutinis LS11 in apples pretreated with this biocontrol agent and infected with Penicillium expansum isolate FS-7. Pooled data from three experiments are presented as mean $10^{7} \mathrm{CFU} / \mathrm{in}-$ fected wound \pm standard deviation of the mean $(n=9)$.

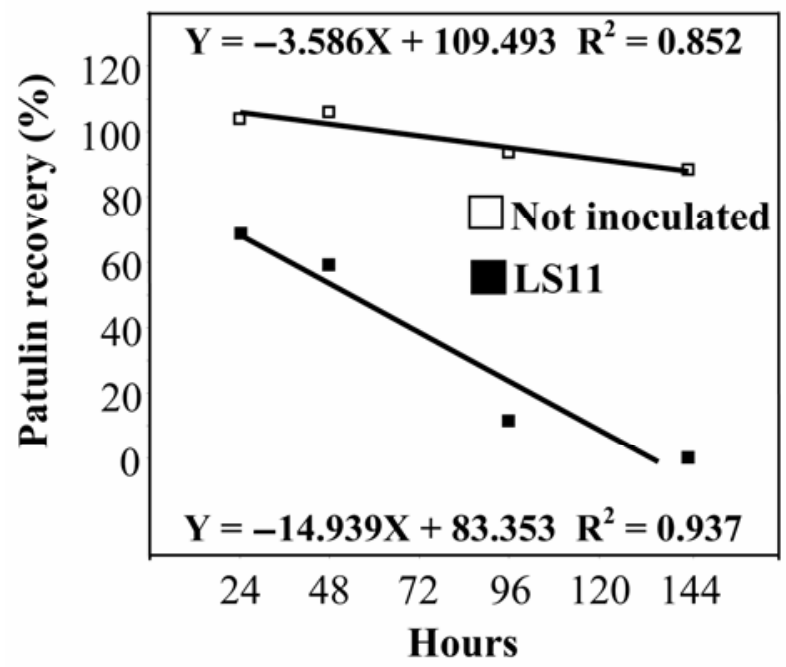

Fig. 6. Time-course of patulin persistence in a pathogen-free model system that emulates decaying apple infected by Penicillium expansum, inoculated (black squares) or not inoculated (white squares) with the biocontrol agent Rhodotorula glutinis LS11. Patulin persistence is expressed as mean percentage of recovery as referred to the amount of toxin added to uninoculated model system and extracted immediately after addition. Regression analysis between percent recovery of patulin and time was performed. Each point represents the mean of three pooled experiments. All means were separated by the least significant difference $(\mathrm{LSD})$ test $(P=0.001)$. LSD $=$ $1.382 \%$. described by linear regression models with highly significant Rsquare coefficients of $0.937\left(P=2.485 \times 10^{-7}\right)$ and $0.852(P=$ $\left.1.882 \times 10^{-5}\right)$ in the presence and absence of LS11, respectively. Both slopes were negative, but absolute value was greater in the presence of $\operatorname{LS} 11(b=-14.939)$ than in its absence $(b=-3.586)$ $(P<0.001)$, indicating that the BCA caused an evident accelerated breakdown of patulin. Factorial analysis showed that the interaction between treatments (absence or presence of LS11) and time was highly significant (data not shown). In LS11-inoculated homogenized apple, patulin recoveries were 69.0 and $58.9 \%$ of the amount added at the beginning of experiments after 24 and $48 \mathrm{~h}$, whereas only $10.9 \%$ and traces of the mycotoxin were recorded at 96 and $144 \mathrm{~h}$, respectively. Conversely, in uninoculated homogenized browning apple tissue, the original amount of patulin was totally recovered after 24 and $48 \mathrm{~h}$, whereas much lower decreases (6.9 and 12.2\%) were recorded at 96 and $144 \mathrm{~h}$.

Interestingly, TLC analyses showed that two major spots appeared in the lanes corresponding to LS11 plus patulin at 48 and $144 \mathrm{~h}$, having the same $\mathrm{R} f$ values as the spots recorded after incubation of the BCA with the toxin in LB medium (Fig. 7). As in the latter experiments, the intensities of these spots increased as that of patulin decreased. As in antagonist activity experiments, cells of LS11 grew and multiplied in the homogenized apple tissue. Colony-forming units increased by approximately a $2 \log$ factor after $24 \mathrm{~h}$, although more steadily in the absence of patulin, and remained stable at the following times (data not shown).

\section{DISCUSSION}

The in vitro screening of three BCAs for their tolerance to patulin was in preparation for in vivo assessments of apples

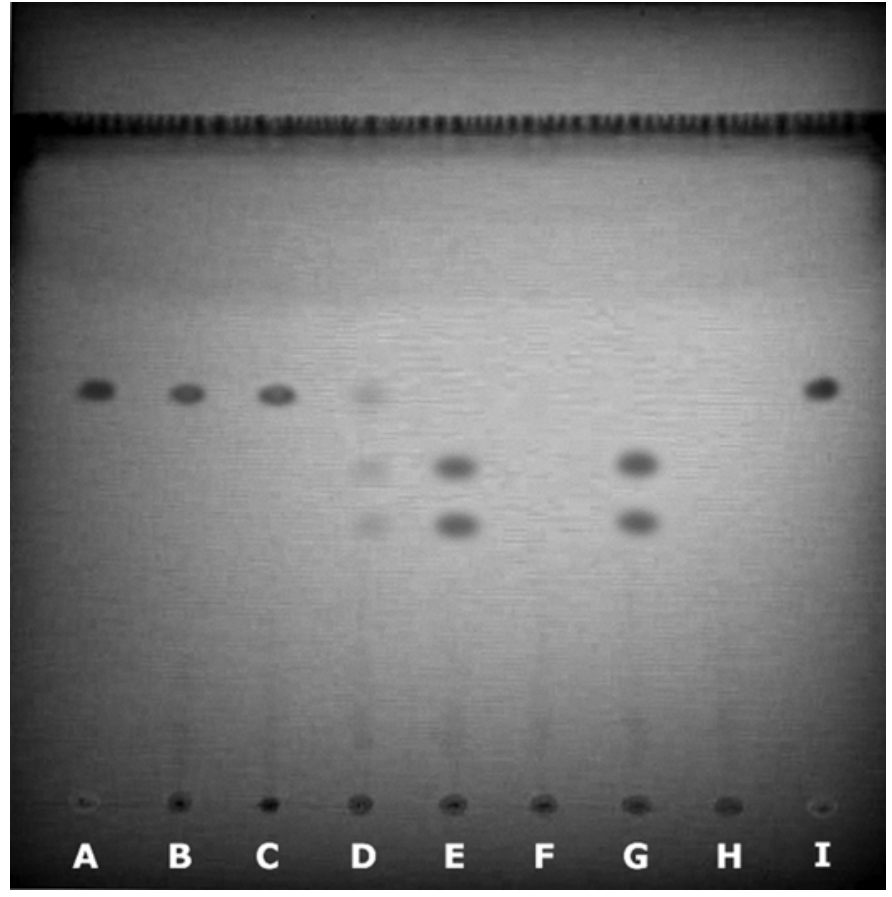

Fig. 7. Thin layer chromatogram of $20-\mu$ l aliquots of unextracted pathogenfree homogenized and browning apple tissue inoculated with the biocontrol agent Rhodotorula glutinis LS11 in the presence of patulin at $250 \mu \mathrm{g} / \mathrm{ml}$. Lanes corresponded to the following samples: patulin plus LS11 at 48 and $144 \mathrm{~h}$ from the beginning of experiments ( $\mathrm{D}$ and $\mathrm{E}$ ); Lanes of control samples were the following: patulin commercial standard $250 \mu \mathrm{g} / \mathrm{ml}$ in acidified water (A and I); patulin $250 \mu \mathrm{g} / \mathrm{ml}$ in uninoculated homogenized and browning apple tissue at 48 and $144 \mathrm{~h}$ from the beginning of experiments (B and C); LS11 inoculated in homogenized browning apple tissue without patulin at $144 \mathrm{~h}$ from the beginning of experiments (F); patulin $250 \mu \mathrm{g} / \mathrm{ml}$ in Lilly-Barnett medium plus LS11 at 10 days from the beginning of in vitro experiments $(\mathrm{G})$; and uninoculated homogenized browning apple tissue without patulin $(\mathrm{H})$. 
infected by $P$. expansum. Rodotorula glutinis strain LS11 was the BCA yielding the highest growth rates in the presence of the mycotoxin and the highest percent decreases of patulin recoveries from the medium. The situation was analogous for the other two BCAs examined in this study, i.e., growth rates of the tested BCAs were higher when lower recoveries of patulin were recorded. These results suggest that metabolization of the toxin could be the main mechanism of tolerance (i.e., growth) of the BCAs to patulin, especially for strain LS11. The in vitro metabolization of patulin is supported by the lack of toxin adsorption to LS11 cell walls, by the total recovery of this compound recorded following incubation with yeast cells autoclaved or killed by sodium azide and, mainly, by the appearance on TLC plates of two new compounds, whose onset and time-course increase paralleled patulin decrease (data not shown). The metabolization of patulin to E-ascladiol by the fermentative yeast $S$. cerevisiae was previously reported by Moss and Long (26). In our study, Rfs of the new unknown compounds were different from those reported for ascladiol (6) and lower than the $\mathrm{R} f$ of patulin. This indicates that, as ascladiol, such putative metabolites have higher polarity than the toxin.

The greatest decrease of patulin recovery occurred following in vitro incubation of this toxin with strain LS11, which led us to ask the following questions. Does this BCA affect patulin accumulation in apples in which $P$. expansum is not affected and infection takes place? And, if so, what mechanism(s) is involved? The BCA LS11 displayed good protection of wounded apples from infections by $P$. expansum, thus confirming previous reports $(20,21)$. Interestingly, patulin accumulation recorded after the same time intervals in infected wounds treated or not with strain LS11 was significantly lower in BCA-treated apples, indicating that BCAs are promising tools to lower patulin contamination during fruit storage. The antagonist activity of LS11 resulted in the reduction of both disease incidence and severity. Further, these cells survived and grew in the decaying apple tissue, even if $P$. expansum was not affected by the BCA. Decaying apple tissue is an "oxidative environment" both for browning due to phenol oxidation generating semiquinone radicals and for reactive oxygen species generated/induced by invading necrotrophic pathogens such as Botrytis cinerea and P. expansum $(13,27,33)$. Survival and growth of LS11 cells is not surprising, since biocontrol yeasts display resistance to oxidative stress as a mechanism of their antagonist activity and can survive in this kind of environment (3). The time-course pattern of symptom development showed that lesion diameters increased with time, although more slowly in BCA-treated apples than in nontreated ones. Lesion diameters can be considered only as a semiquantitative index of pathogen growth in decaying fruit tissue. However, it is conceivable that the retardation of lesion development due to surviving BCA cells reflects a delay of fungal growth in the decaying tissue. Such a delay could be a possible mechanism accounting, at least partially, for the reduction of toxin accumulation in LS11-treated apples.

Further experiments with a model system emulating decaying tissue were aimed at gaining more insight into the possible mechanism(s) of patulin reduction. Pathogen-free macerated browning apple is a simplified model system, since it does not take into account the influence of $P$. expansum on patulin reduction by LS11. In this system, however, LS11 caused a significant decrease of exogenously applied patulin, suggesting that the environment represented by the decaying apple tissue does not inhibit toxin reduction by this BCA. Further, two major putative metabolites similar to those detected in in vitro experiments were detected. These unknown compounds displayed a time-course increase paralleling patulin decrease. These findings support the possibility that the metabolization of the toxin by the BCA also occurs in infected apples. Additional evidence is needed to demonstrate patulin metabolization by the BCA during the apple- pathogen-biocontrol yeast interaction in infected apples, namely the presence of the same metabolites as those recorded in in vitro experiments and in experiments carried out with pathogen-free homogenized browning apple. These compounds are under purification and characterization, and appropriate analytical procedures for their detection and quantification are being developed. Patulin metabolization in infected apples implies physical contact between the toxin and LS11 cells. This BCA is known to adhere to fungal hyphae in vitro (5), but we do not know if such adhesion occurs and continues on infected apples as $P$. expansum penetrates into fruit tissue. On the other hand, various reports show that patulin diffuses from rotting areas of apple to parts unaffected by the fungus $(1,30)$, and that this diffusion is greater in fruit tissues with lower content of structure-forming polysaccharides and looser texture (8). Lytic enzymes of $P$. expansum attack structural polysaccharides and cause tissue maceration in rotting areas of infected apples $(28,35)$. Under these conditions, it is conceivable that LS11 cells, present either within or on the surface of rotting apple parts, gain physical contact with at least part of the diffusing patulin.

In this study, experiments were performed at room temperature, but further investigations are necessary under cold storage condition. However, systems lowering mycotoxin accumulation at room temperature could represent valuable tools for developing countries where cold storage facilities are not widespread and fruit contamination with mycotoxins causes a serious health hazard as well as significant economic losses (8).

In summary, this study demonstrates that a postharvest biocontrol yeast appears to metabolize patulin in vitro and in a model system emulating decaying apple tissue. Further, the BCA is able to decrease accumulation of this toxin in $P$. expansum-infected apples. Such decrease is apparently due to a retardation of pathogen development in BCA-treated decaying apples and, possibly, to metabolization of patulin by the BCA under these conditions, but the latter mechanism is to be confirmed. Characterization and purification of the compounds produced by the BCA are in progress, in order to develop the appropriate analytical procedures confirming metabolization of patulin by the BCA in infected apples and to perform toxicological assessments. Provided that the metabolites produced by the biocontrol yeast have lower toxicity than patulin, the identification of the gene(s)/enzyme(s) responsible for toxin conversion could pave the way for the development of new technologies for the prevention and/or detoxification of patulin contamination in apple-based juices.

\section{ACKNOWLEDGMENTS}

We dedicate this work to our brilliant colleague and friend who died recently, Giovanni Del Sorbo. We thank A. Visconti for critically reading the manuscript, S. Vanadia for valuable advice on statistical elaboration of data, and M. O. Moss for information about ascladiol and G. Lima for his key role in establishing the culture collection used in this study. This research was funded by the Italian Ministry of Education, University and Scientific Research, Project PRIN n. 2002073389 "Fungal pathogens of harvested fruits and vegetables and antagonistic microorganisms: modes of action, ecology, optimization of antagonistic activity."

\section{LITERATURE CITED}

1. Beretta, B., Gaiaschi, A., Galli, C. L., and Restani, P. 2000. Patulin in apple-based foods: Occurrence and safety evaluation. Food Addit. Contam. 17:399-406.

2. Bourdiol, D., and Escoula, L. 1990. Effect of patulin on microbicidal activity of mouse peritoneal macrophages. Food Chem. Toxicol. 28:29-33.

3. Castoria, R., Caputo, L., De Curtis, F., Lima, G., and De Cicco, V. 2003. Resistance to oxidative stress of postharvest biocontrol yeast: A possible new mechanism of action. Phytopathology 93:564-572.

4. Castoria, R., De Curtis, F., Lima, G., Caputo, L., Pacifico, S., and De Cicco, V. 2001. Aureobasidium pullulans (LS-30) an antagonist of postharvest pathogens of fruits: Study on its modes of action. Postharvest Biol. Technol. 22:7-17. 
5. Castoria, R., De Curtis, F., Lima, G., and De Cicco, V. 1997. $\beta-1,3-$ Glucanase activity of two saprophytic yeasts and possible mode of action involved as biocontrol agents against postharvest diseases. Postharvest Biol. Technol. 12:293-300.

6. Cole, R. J., and Cox, R. H. (eds.) 1981. Toxic Lactones. Pages 210-526 in: Handbook of Toxic Fungal Metabolites. Academic Press, New York.

7. Droby, S. 2001. Enhancing biocontrol activity of microbial antagonists of postharvest diseases. Pages 77-85 in: Enhancing Biocontrol Agents and Handing Risks. M. Vurro, J. Gressel, T. Butt, G. Harman, A. Pilgeram, R. St. Leger, and D. Nuss, eds. IOS Press, Amsterdam, The Netherlands.

8. Drusch, S., and Ragab, W. 2003. Mycotoxins in fruits, fruit juices, and dried fruits. J. Food Prot. 66:1514-1527.

9. European Commission (EC). 2004. Regulation (EC) No 455/2004 amending Regulation (EC) No 466/2001 as regards patulin. Official J. Eur. Union L74:11.

10. Food and Agriculture Organization (FAO). 1997. World wide regulations for mycotoxins. A compendium. Food and Nutrition Paper No. 64, Food and Nutrition Division, FAO, Rome, Italy.

11. Food and Agriculture Organization (FAO)/WHO. 2002. Proposed draft code of practice for the prevention of patulin contamination in apple juice and apple juice ingredients in other beverages. Pages 1-8 in: Joint FAO/WHO Food Standards Programme Reports, Codex Committee on Food Additives and Contaminants, 34th Session, Rotterdam, The Netherlands, FAO, Rome, Italy.

12. Grevesse, C., Lepoivre, P., and Jijakli, H. 2003. Characterization of the exoglucanase-encoding gene PaEXG2 and study of its role in the biocontrol activity of Pichia anomala strain K. Phytopathology 93:1145-1152.

13. Hadas, Y., Goldberg, I., Pines, O., and Prusky, D. 2004. Tissue acidification by Penicillium as a mechanism to enhance pathogenicity. Page 118 in: Proc. 7th European Conference on Fungal Genetics, Workshop IV Signal Transduction. Copenhagen, Denmark.

14. Harwig, J., Scott, P. M., Kennedy, B. P. C., and Chen, Y. K. 1973. Disappearance of patulin from apple juice fermented by Saccharomyces spp. Can. Inst. Food Sci. Technol. J. 6:45-46.

15. International Agency for Research on Cancer (IARC). 1986. Patulin. Pages 83-98 in: Monograph No. 40 on the evaluation of carcinogenic risk of chemicals to man. IARC, Lyon, France.

16. Ippolito, A., and Nigro, F. 2000. Impact of preharvest application of biological control agents on postharvest diseases of fresh fruits and vegetables. Crop Prot. 19:715-723.

17. Janisiewicz, W. J., and Korsten, L. 2002. Biological control of postharvest diseases of fruits. Annu. Rev. Phytopathol. 40:411-441.

18. Larsen, T. O., Frisvad, J. C., Ravn, G., and Skaaning, T. 1998. Mycotoxin production by Penicillium expansum on blackcurrant and cherry juice. Food Addit. Contam. 15:671-675.

19. Lilly, V. G., and Barnett, H. L. 1951. Physiology of the fungi. McGrawHill, New York.

20. Lima, G., De Curtis, F., Castoria, R., and De Cicco, V. 1998. Activity of the yeasts Cryptococcus laurentii and Rhodotorula glutinis against postharvest rots on different fruits. Biocontrol Sci. Technol. 8:257-267.
21. Lima, G., De Curtis, F., Castoria, R., and De Cicco, V. 2003. Integrated control of apple postharvest pathogens and survival of biocontrol yeasts in semi-commercial conditions. Eur. J. Plant Pathol. 109:341-349.

22. Liu, B. H., Yu, F. Y., Wu, T. S., Li, S. Y., Su, M. C., Wang, M. C., and Shih, S. M. 2003. Evaluation of genotoxic risk and oxidative DNA damage in mammalian cells exposed to mycotoxins, patulin and citrinin. Toxicol. Appl. Pharmacol. 191:255-263.

23. Lopez-Garcia, B., Gonzales-Candelas, L., Perez-Paya, E., and Marcos, J. F. 2000. Identification and characterization of a hexapeptide with activity against phytopathogenic fungi that cause postharvest decay in fruits. Mol. Plant-Microbe Interact. 13:837-846.

24. MacDonald, S., Long, M., and Gilbert, J. 2000. Liquid Chromatographic method for determination of patulin in clear and cloudy apple juices and apple puree: Collaborative study. J. AOAC Int. 83:1387-1394.

25. Medical Research Council. 1944. Clinical trial of patulin in the common cold: Report of the patulin Clinical Trials Committee. Lancet 2:373375.Moss, M. O., and Long, M. T. 2002. Fate of patulin in the presence of yeast Saccharomyces cerevisiae. Food Addit. Contam. 19:387-399.

27. Prins, T., Tudzinsky, P., Von Tiedemann, A., Tudzinsky, B., Ten Have, A., Hansen, M. E., Tenberge, K., and Van Kann, J. A. L. 2000. Infection strategies of Botrytis cinerea and related necrotrophic pathogens. Pages 33-64 in: Fungal Pathology. J. W. Kronstad, ed. Kluwer Academic Publishers, Dordrecht, The Netherlands.

28. Prusky, D., McEvoy, J. L., Saftner, R., Conway, W. S., and Jones, R. 2004. Relationship between acidification and virulence of Penicillium spp. on apple and citrus fruit. Phytopathology 94:44-51.

29. Ritieni, A. 2003. Patulin in Italian commercial apple products. J. Agric. Food Chem. 51:6086-6090.

30. Rychlik, M., and Schieberle, P. 2001. Model studies on the diffusion behavior of the mycotoxin patulin in apples, tomatoes, and wheat bread. Eur. Food Res. Technol. 212:274-278.

31. Spotts, R. A., and Cervantes, L. A. 1986. Populations, pathogenicity, and benomyl resistance of Botrytis spp., Penicillium spp., and Mucor piriformis in packinghouses. Plant Dis. 70:106-108.

32. Suzuki, T., Takeda, M., and Tanabe, H. 1971, A new mycotoxin produced by Aspergillus clavatus. Chem. Pharm. Bull. 19:1786-1788.

33. Tiedemann, A. V. 1997. Evidence for a primary role of active oxygen species in induction of host cell death during infection of bean leaves with Botrytis cinerea. Physiol. Mol. Plant Pathol. 50:151-166.

34. Wilson, C. L., and Wisnieswski, M. E. 1992. Futures alternatives to synthetic fungicides for the control of postharvest diseases. Pages 133148 in: Biological Control of Plant Disease. E. C. Tjamos, G. C. Papavizas, and R. J. Cook, eds. Plenum Press, New York.

35. Yao, C., Conway, W. S., and Sarns, C. E. 1996. Purification and characterization of a polygalacturonase produced by Penicillium expansum in apple fruit. Phytopathology 86:1160-1166.

36. Yehuda, H., Droby, S., Bar-Shimon, M., Wisnievski, M., and Goldway, M. 2003. The effect of under- and overexpressed CoEXG1-encoded exoglucanase secreted by Candida oleophila on the biocontrol of Penicillium digitatum. Yeast 20:771-780. 